Article

\title{
Thermal Conductivity of an AZ31 Sheet after Accumulative Roll Bonding
}

\author{
Zuzanka Trojanová ${ }^{1, *(1)}$, Kristýna Halmešová ${ }^{2}$ (D), Zdeněk Drozd ${ }^{1}$, Vladimír Šíma ${ }^{1}$ (D), \\ Pavel Lukáč ${ }^{1}$, Ján Džugan ${ }^{2}$ and Peter Minárik ${ }^{1}$ (iD \\ 1 Faculty of Mathematics and Physics, Charles University, Ke Karlovu 3, 12116 Praha 2, Czech Republic; \\ zdenek.drozd@mff.cuni.cz (Z.D.); sima@met.mff.cuni.cz (V.Š.); lukac@met.mfff.cuni.cz (P.L.); \\ peter.minarik@mff.cuni.cz (P.M.) \\ 2 COMTES FHT, Průmyslová 996, 33441 Dobřany, Czech Republic; kristyna.halmesova@comtesfht.cz (K.H.); \\ jdzugan@comtesfht.cz (J.D.) \\ * Correspondence: ztrojan@met.mff.cuni.cz; Tel.: +420-95155-1648
}

Received: 28 April 2018; Accepted: 29 June 2018; Published: 2 July 2018

\begin{abstract}
Accumulative roll bonding (ARB) is one of the methods of severe plastic deformation which is relevant for industrial production of sheets. While mechanical properties of several magnesium alloys subjected to the ARB process have been studied, the physical properties have been reported only for some magnesium alloys. These properties are influenced by the texture developed during the ARB process and the temperature load. In the presented contribution, we studied thermal conductivity of an AZ31 magnesium alloy after one and two passes through the rolling mill. Thermal diffusivity was measured with the laser-flash method in the temperature range between 20 and $350{ }^{\circ} \mathrm{C}$. Thermal conductivity depends on the number of rolling passes. The microstructure and texture of sheets are significant factors influencing thermal properties.
\end{abstract}

Keywords: magnesium alloy; accumulative roll bonding; thermal conductivity; texture

\section{Introduction}

Mg-Al-Zn alloys, due to their low density and high specific strength, belong to the most used magnesium materials. The strength of these alloys increases with increasing the Al content. An AZ31 alloy can be applied as wrought alloy. The mechanical properties of Mg-Al-Zn alloys can be improved using methods of severe plastic deformation (SPD) due to Hall-Petch strengthening. Several SPD methods have been described among them methods based on the rolling process as differential speed rolling (DSR) [1,2], single roller drive rolling (SRDR) [3] or accumulative roll bonding (ARB) [4-6]. ARB allows preparing big sheets with a predetermined thickness. On the other hand, such materials exhibit developed planar anisotropy of mechanical properties as a consequence of the texture formed during the rolling process. The texture influence on properties of hexagonal magnesium materials is significant due to large anisotropy of magnesium itself. The anisotropy of mechanical properties has been reported several times in the literature [7-9]. Furthermore, the developed texture affects not only mechanical properties (strength, modulus) but also physical properties (thermal expansion coefficient, internal friction, electrical resistivity). The effect of the texture on thermal properties was studied only rarely [10-13].

Thermal properties of alloys belong to the important characteristics of structural materials. Dimensional stability and distribution of the heat in the thermally loaded devices are problems of the highest priority. Thermal properties of a material influence the chilling effect (a sudden decrease of surface temperature after contact with rollers) observed during the rolling process. This chilling effect is relatively high in magnesium alloys due to their low specific heat capacity. Temperature 
distribution in the rolled sheets is affected by heat produced by plastic deformation, inside conduction, friction heat, convection and radiation to the environment. These factors may lead to the heterogeneous temperature distribution in a material (cit. $[14,15])$. Furthermore, plastic deformation mechanisms strongly depend on temperature; thus the inhomogeneous temperature field in the sheet leads also to non-uniform strain. In this study the temperature dependence of the thermal conductivity of a magnesium alloy AZ31 is measured with the aim to estimate the effect of the ARB process on thermal conductivity.

\section{Materials and Methods}

AZ31 (commercial purity) magnesium alloy sheets with initial thickness of $2 \mathrm{~mm}$ were used in this study. Table 1 shows the chemical composition of the used AZ31 alloy. Before the rolling, the surfaces of the sheets were wire brushed and clean with acetone in order to obtain oxide free surface with appropriate roughness for high-quality joints. The sheets were riveted along one side to bring the cleaned surfaces in contact. Then the sheets were annealed at $400{ }^{\circ} \mathrm{C}$ for $15 \mathrm{~min}$. Four-high rolling mill configuration with the rolling speed of $0.4 \mathrm{~ms}^{-1}$ and $50 \%$ rolling reduction in each pass was used. We performed one and two passes through the rolling mill. ARB_1 and ARB_2, respectively indicate the samples subjected to one or two passes of the ARB process. ARB_0 stands for the as-received sheet.

Table 1. Chemical composition of the alloy in $\mathrm{wt} \%$.

\begin{tabular}{ccccccc}
\hline Al & Zn & Mn & Si & Ce & Fe & Mg \\
\hline 3.16 & 1.29 & 0.41 & $0.01_{5}$ & $0.05_{5}$ & 0.02 & Bal. \\
\hline
\end{tabular}

Laser flash method LINSEIS LFA 1000 was applied for the thermal diffusivity and specific heat measurements ranging from 20 up to $350{ }^{\circ} \mathrm{C}$ under vacuum environment. The dimensions of the specimens were $12.7 \mathrm{~mm}$ in diameter and $2 \mathrm{~mm}$ in thickness and the measurement was performed across the sample thickness. The samples were coated with graphite on both sides to ensure homogenous absorption of the laser energy. Four samples were measured simultaneously three times; for each sample the median of the three values was taken and then the mean value and the standard deviation was calculated. The main principle of the thermal diffusivity measurements is to measure the temperature rise on the rear side of the samples with liquid-nitrogen cooled infrared detector after the laser pulse. Then, the thermal diffusivity coefficient $a$ is calculated according to the formula: $a=0.1388 \cdot \ell^{2} / t_{0.5}$, where $\ell$ is the thickness of the specimen and $t_{0.5}$ is the time at $50 \%$ of temperature increase. For the specific heat measurement, comparison method was used. Pure Molybdenum (3N8) was used as a reference sample. Then, the specific heat coefficient corresponds to the total temperature increase according to the formula: $c_{\mathrm{p}}=c_{\mathrm{pr}}\left(\Delta \mathrm{T}_{\mathrm{r}} / \Delta \mathrm{T}\right)\left(\mathrm{m}_{\mathrm{r}} / \mathrm{m}\right)$, where $c_{\mathrm{p}}, c_{\mathrm{pr}}$ are the specific heats of the sample and reference sample; $\Delta \mathrm{T}, \Delta \mathrm{T}_{\mathrm{r}}$ are temperature increases induced by the laser pulse; $\mathrm{m}, \mathrm{m}_{\mathrm{r}}$ are the masses of the sample and reference sample, respectively.

The thermal expansion coefficient, $\alpha$, was measured using a LINSEIS L75PT-1600 dilatometer at heating and cooling rates of $1 \mathrm{~K} / \mathrm{min}$ in a resistance furnace in an argon protective atmosphere. Length changes were measured by linear variable differential transformer (LVDT) sensor through quartz push-rods. $\mathrm{Al}_{2} \mathrm{O}_{3}$ reference was used for correction measurements.

Density of the samples was estimated by the hydrostatic weighing at room temperature. Microstructure characteristics and the texture of samples were studied using light microscopes (OLYMPUS and NEOPHOT) and by a FEI Quanta 200 FX scanning electron microscope equipped with EDAX EBSD system; orientation imaging map software was utilized for EBSD observations. The step size used for EBSD measurements was $0.8 \mu \mathrm{m}$. 


\section{Results}

\subsection{Microstructure of Samples}

Light micrographs taken from the sheets surface of the ARB_0, ARB_1 and ARB_2 samples are depicted in Figures 1-3. Non-uniform grain structure consisting of bigger grains surrounded by small grains was found in the rolled sheet (Figure 1). After the first ARB process the grain structure was refined as it is obvious from Figure 2, nevertheless it remained still non-uniform. The result of the second ARB pass is shown in Figure 3. As can be seen the microstructure is nearly uniform with fine grains.

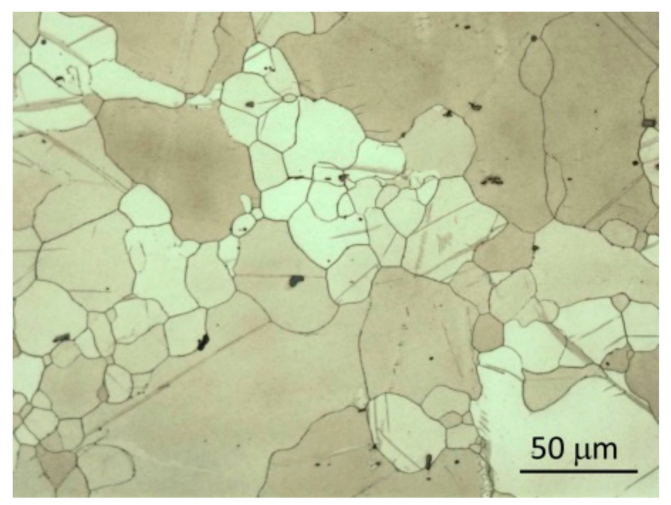

Figure 1. Microstructure taken from the ARB_0 surface.

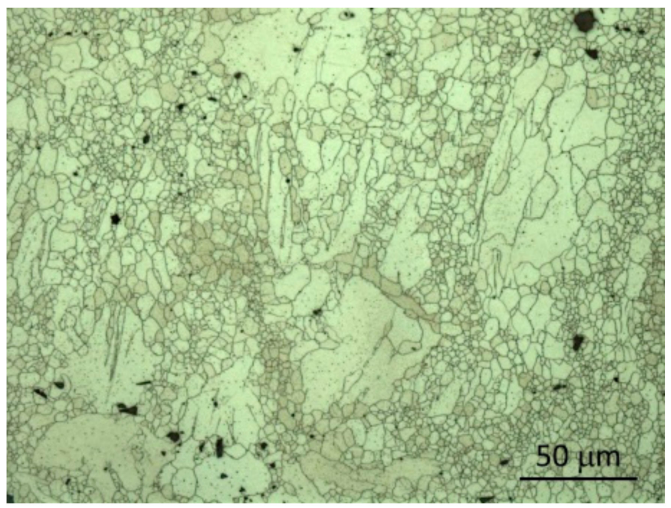

Figure 2. Microstructure taken from the ARB_1 surface.

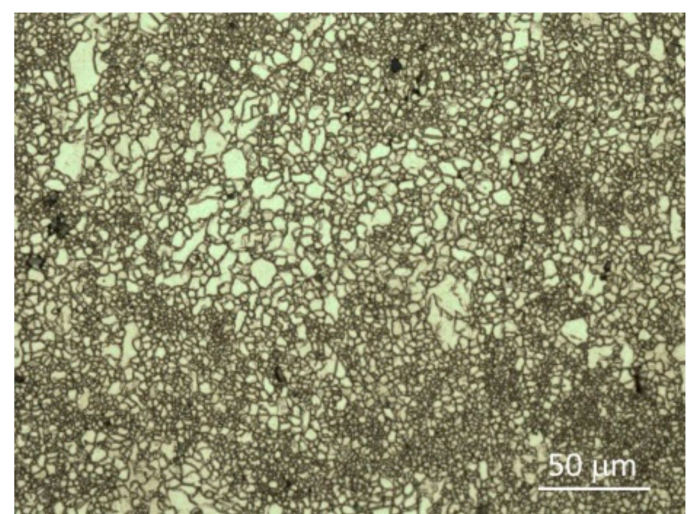

Figure 3. Microstructure taken from the ARB_2 surface. 
Particles visible in Figures 1-3 were analyzed using EDX line spectroscopy. Particles represent an Al-Mn binary phase. In the literature, these particles were identified as $\mathrm{Al}_{8} \mathrm{Mn}_{5}$ and $/$ or $\mathrm{Al}_{11} \mathrm{Mn}_{4}$ phases $[16,17]$. A new interface formed in the ARB process is visible in the light micrograph presented in Figure 4.

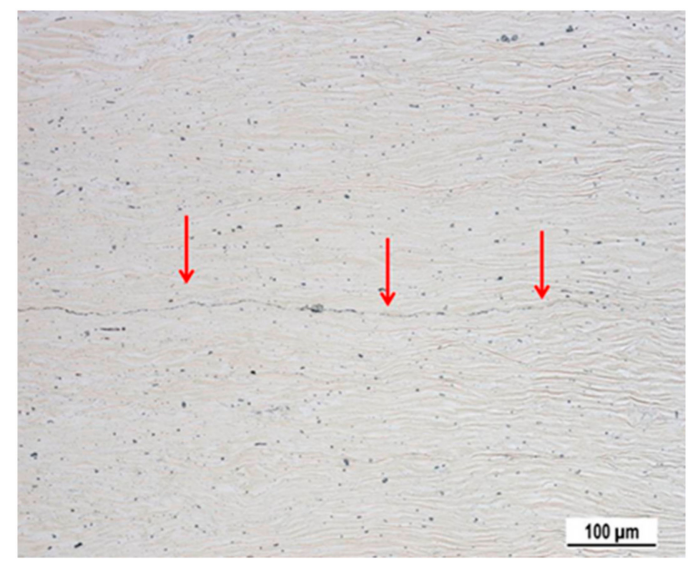

Figure 4. New interface formed in the ARB_1 sample.

\subsection{Thermal Measurements}

The thermal conductivity $\kappa(\mathrm{W} /(\mathrm{m} \mathrm{K}))$ can be calculated according to known relationship

$$
\kappa=a \cdot \rho \cdot c_{\mathrm{p}}
$$

where $a$ is the thermal diffusivity $\left(\mathrm{cm}^{2} / \mathrm{s}\right), \rho$ is the density $\left(\mathrm{kg} \mathrm{m}^{-3}\right), c_{\mathrm{p}}$ is the specific heat capacity $(\mathrm{J} / \mathrm{kg} / \mathrm{K})$ at constant pressure. Taking into account the thermal expansivity of the sample thickness and volume

$$
\ell=\ell_{20}[1+\alpha \cdot(T-20)]
$$

we obtained for the sample density the following relationship

$$
\rho=\rho_{20} /[1+\alpha \cdot(\mathrm{T}-20)]^{3} \text {. }
$$

The thermal conductivity can be calculated according to formula:

$$
\kappa=\frac{0.1388 \cdot \downarrow_{20}^{2}}{t_{0.5}(T)} \rho_{20} c_{p}(T) /[1+\alpha \cdot(T-20)]
$$

\begin{tabular}{|c|c|c|c|c|c|c|}
\hline \multirow{2}{*}{$\begin{array}{c}\text { Material } \\
\mathrm{T}\left({ }^{\circ} \mathrm{C}\right)\end{array}$} & \multicolumn{2}{|c|}{ ARB_0 } & \multicolumn{2}{|c|}{ ARB_1 } & \multicolumn{2}{|c|}{ ARB_2 } \\
\hline & $\begin{array}{c}{ }^{c_{\mathrm{p}}} \\
\left(\mathrm{Jkg}^{-1} \mathrm{~K}^{-1}\right)\end{array}$ & $\begin{array}{c}\alpha \times 10^{-6} \\
\left(\mathrm{~K}^{-1}\right)\end{array}$ & $\underset{\left(\mathrm{Jkg}^{-1} \mathrm{~K}^{-1}\right)}{c_{\mathrm{p}}}$ & $\begin{array}{c}\alpha \times 10^{-6} \\
\left(\mathrm{~K}^{-1}\right)\end{array}$ & $\left(\mathrm{Jkg}^{-1}{ }^{c_{\mathrm{p}}} \mathrm{K}^{-1}\right)$ & $\begin{array}{c}\alpha \times 10^{-6} \\
\left(\mathrm{~K}^{-1}\right)\end{array}$ \\
\hline 20 & 1010 & 26.53 & 1002 & 26.27 & 1036 & 25.73 \\
\hline 50 & 1012 & 26.72 & 1037 & 26.47 & 1087 & 25.94 \\
\hline 100 & 1060 & 27.04 & 1070 & 26.80 & 1101 & 26.31 \\
\hline 150 & 1090 & 27.36 & 1107 & 27.12 & 1133 & 26.67 \\
\hline 200 & 1112 & 27.68 & 1120 & 27.45 & 1159 & 27.04 \\
\hline 250 & 1130 & 27.99 & 1113 & 27.77 & 1186 & 27.40 \\
\hline 300 & 1161 & 28.31 & 1146 & 28.10 & 1186 & 27.77 \\
\hline 350 & 1184 & 28.63 & 1166 & 28.43 & 1203 & 28.13 \\
\hline
\end{tabular}

Experimental values of the specific heat, $c_{\mathrm{p}}$, and the thermal expansion coefficient, $\alpha$, used for the calculation, are reported in Table 2.

Table 2. Specific heat, $c_{\mathrm{p}}$, and thermal expansion coefficient, $\alpha$, estimated at various temperatures. 
The temperature dependence of the thermal conductivity is shown in Figure 5. The thermal conductivity increases with increasing number of passes at all temperatures. This is better seen in Figure 6 where the thermal conductivity, measured at room temperature, rapidly increases with increasing number of passes.

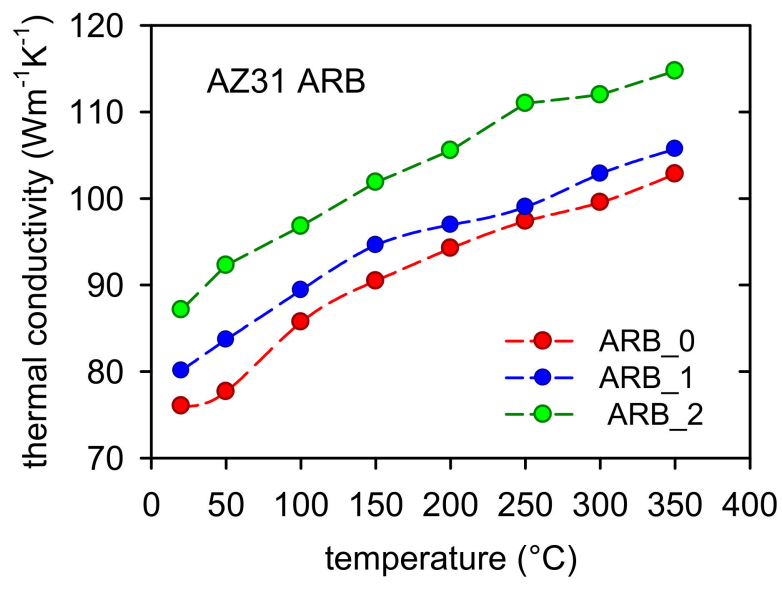

Figure 5. Temperature dependence of thermal conductivity.

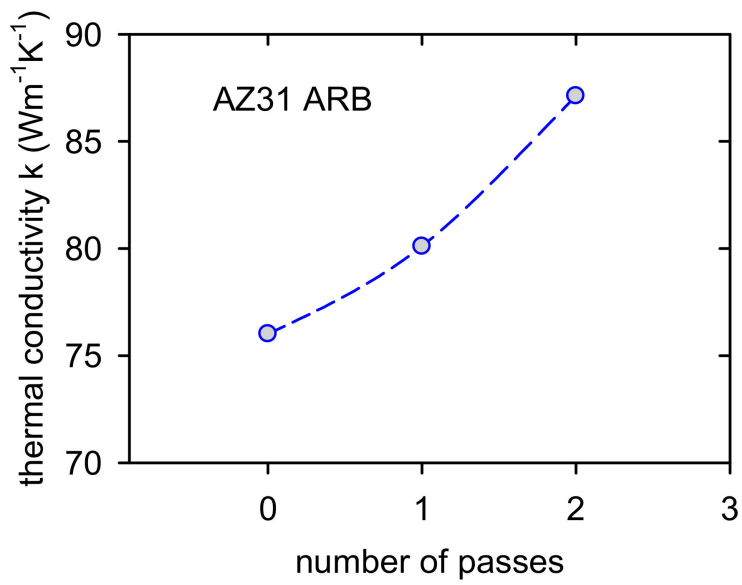

Figure 6. Thermal conductivity estimated at room temperature depending on number of passes.

\section{Discussion}

The conductivity of magnesium alloys has been reported in many papers. Mostly, binary and ternary magnesium alloys consist of $\alpha$-grains containing the solid solution of the alloying elements in $\mathrm{Mg}$ and various phases. Generally, the thermal conductivity depends on their composition and thermal history [9,11,13,18-29]. Results of these studies were ambiguous. Ying et al. [9] studied extruded Mg-Al alloys in the temperature interval ranging from room temperature up to $250{ }^{\circ} \mathrm{C}$. Presented results show that thermal conductivity of pure $\mathrm{Mg}$ and $\mathrm{Mg}-0.5 \mathrm{at} . \% \mathrm{Al}$ decreases with increasing temperature, while the thermal conductivity of $\mathrm{Mg}-0.9 \mathrm{at} . \% \mathrm{Al}$ remains almost unchanged, and the thermal conductivity of $\mathrm{Mg}-1.5 \mathrm{at} . \% \mathrm{Al}$ increases with increasing temperature. Similar results were found for $\mathrm{Mg}-\mathrm{Zn}$ alloys [11]. For $\mathrm{Zn}$ contents higher than $1 \mathrm{wt} . \%$, thermal conductivity increases with increasing temperature from 30 up to $240{ }^{\circ} \mathrm{C}$. Precipitation of the second phase particles increases thermal conductivity due to purification of the matrix [23]. Thermal conductivity of an AZ31 alloy prepared by twin roll casting was measured in a wide temperature range from $-125^{\circ} \mathrm{C}$ up to $400{ }^{\circ} \mathrm{C}$ [23]. Thermal conductivities estimated by Lee et al. in [22] and our results of ARB_0 are shown in Figure 7. It can be seen that the obtained results are very close, even if different processing conditions were used. 


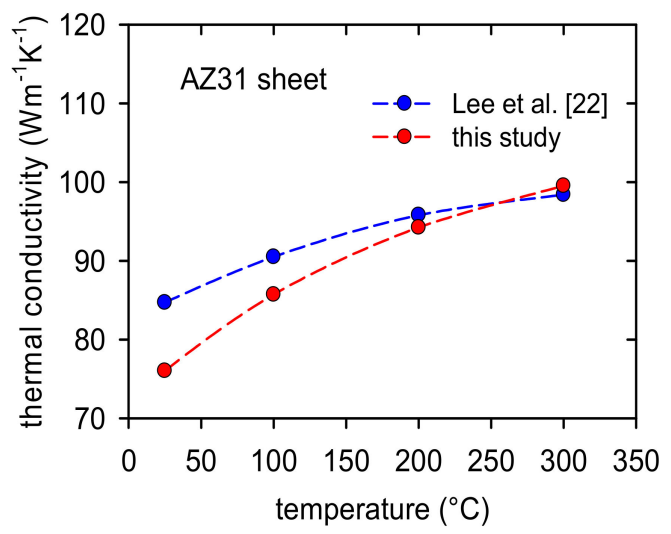

Figure 7. Thermal conductivity of rolled sheets.

As it was shown in several papers, the microstructure and microstructure changes influence the thermal conductivity $[12,13,18-29]$. The main changes in the microstructure occurred during the ARB process are grain refinement and development of the texture. While the grain refinement influence on the thermal conductivity was according to authors knowledge not systematically studied, the influence of texture was observed by several authors $[10-13,28]$. Ying et al. studied extruded $\mathrm{Mg}$ and $\mathrm{Mg}-\mathrm{Zn}$ alloys. They estimated that thermal conductivity of the pure $\mathrm{Mg}$ and $\mathrm{Mg}-\mathrm{x} \% \mathrm{Zn}(\mathrm{x}=0.5-5 \% \mathrm{Zn})$ is lower in the extrusion direction comparing with the transversal direction [11]. The orientation effect was significant for pure $\mathrm{Mg}$ and weaker in the $\mathrm{Mg}+5 \% \mathrm{Zn}$ alloy. Thermal conductivity of cast and extruded ZM51 alloy was studied by Yuan et al. at room temperature [29]. They estimated distinctive influence of the texture on thermal conductivity developed during the extrusion procedure. The thermal conductivity value estimated in the extrusion direction was lower than values measured in both transversal and normal directions. The isotropic value found for the cast sample was the highest. It is very probably due to influence of the grain size. Increased density of grain boundaries in the extruded samples restricts the mean free path of electrons and decreases thermal conductivity. The same effect must be considered in the AZ31 sheets after the ARB procedure. There are two competitive processes: decreased grain size (and hence increased density of the gain boundaries) and the rolling texture. Presented experimental results documented that the influence of the material anisotropy is stronger.

Rolled sheets from magnesium materials exhibit a typical texture, where basal planes (0001) are mostly parallel to the sheet surface. It is due to operation of various slip systems during the rolling deformation. Basal and prismatic slip can operate parallel to the rolling direction and width direction, but not parallel to the thickness direction.

Observed textures of our samples are presented in Figure 8a for ARB_0, Figure 8b (ARB_1) and Figure 8c (ARB_2).

a)

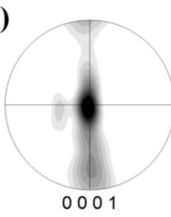

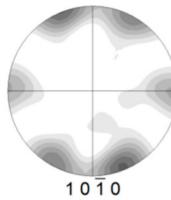

c)

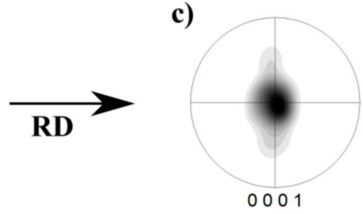

b)
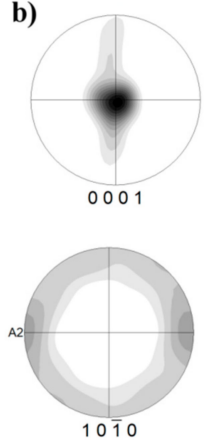

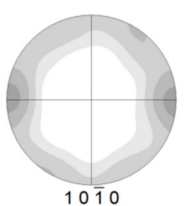

$\mathbf{O}^{6}$
$\mathbf{E}^{4}$
$\mathrm{~B}^{3}$
$\mathrm{E}^{2}$

Figure 8. Texture of ARB_0 (a), ARB_1 (b) and ARB_2 samples (c). 
After the repeated rolling in the first and second pass, the grain refinement occurred in a continuous rotational dynamic recrystallization (RRX) process. This mechanism involves dynamic polygonization of rotated lattice regions adjacent to the grain boundaries $[30,31]$. The texture after the first and the second pass is nearly perfect (Figure 8), i.e., most grains are oriented with their basal planes parallel to the sheet surface. The estimated texture indicates that thermal conductivity of the rolled samples cannot be explained considering samples as the isotropic materials.

Thermal conductivity can be attributed to the heat transport by electrons and by phonons. When both can be considered as independent then: $\kappa=\kappa_{e}+\kappa_{p h}$. The maximum in the phonon part $\kappa_{p h}$ is typically at temperature about $0.1 \theta_{D}, \theta_{D}$ is the Debye temperature of a material $\left(\theta_{\mathrm{D}}(\mathrm{Mg})=318 \mathrm{~K}\right)$ [32]. It means that the measured thermal conductivity in our case can be attributed to the electronic contribution $\kappa_{e}$. According to the Wiedemann-Franz law [33]

$$
\kappa_{e}=\mathrm{L}_{0} \cdot \sigma \cdot \mathrm{T},
$$

where $\sigma$ is the electrical conductivity and $\mathrm{L}_{0}$ is the standard Lorentz number and $\mathrm{T}$ absolute temperature. For highly degenerated systems such as metals $\mathrm{L}_{0}=2.45 \times 10^{-8} \mathrm{~W} \Omega \mathrm{K}^{-2}$ [34]. Supposing a weak temperature dependence of electrical conductivity due to temperature independent scattering on impurities and defects [34], we can simply explain the measured increasing temperature dependence of the thermal conductivity (Figure 5).

In a conductor, the electronic conductivity $\kappa_{\mathrm{e}}$ (either electric or thermal) is defined as

$$
J=\kappa_{\mathrm{e}} \cdot E,
$$

where $J$ is the flow density (electric current density or heat flow density) and $E$ the field (electric field or temperature gradient). Generally the conductivity is a tensor. Non scalar conductivity can be found also in materials with hexagonal symmetry. Bass [35] estimated that the electrical conductivity of a magnesium single crystal along the $\langle c\rangle$ axis is higher than that in the $\langle a>$ direction, i.e., we can also expect for the thermal conductivity, $\kappa(c) / \kappa(a)>1$.

In the textured sheet, the hexagonal cells are preferentially oriented such that the $\langle c\rangle$ axis is perpendicular to the sheet surface. Thermal conductivity was measured in the same orientation, i.e., in directions preferentially close to the $<c>$ direction. The texture strengthening after the first and second passes increased the number of grains oriented with the $\langle c>$ axis perpendicular to the sheet surface, therefore, resulting in an increase in thermal conductivity. In $\mathrm{Mg}$, where basal planes are close packed, the mean free path of electrons is higher in the $\langle c\rangle$ direction than in the basal plane. It should be mentioned that the anisotropy of electrical conductivity of hexagonal metals increases with increasing the $\langle c>/<a>$ ratio [35].

\section{Conclusions}

Thermal conductivity of AZ31 magnesium alloy was measured in the temperature range from room temperature up to $350{ }^{\circ} \mathrm{C}$. Samples for the conductivity measurements were prepared by accumulative roll bonding. The conductivity measurements were performed in the direction perpendicular to the sheet surface.

- ARB process refined the sheets microstructure.

- Rolled sheets exhibit developed texture where basal planes (0001) are preferentially parallel to the sheet surface.

- Thermal conductivity increases with temperature and increasing number of rolling passes.

- The observed increase of thermal conductivity with the increasing number of rolling passes can be explained with the texture improvement and anisotropy of thermal properties of magnesium.

- This anisotropy can be of advantage in cases where the heat dissipation occurs in one direction. 
Author Contributions: Z.T. conceived and designed the experiments; K.H. and J.D. performed ARB procedure; Z.D. and K.H. measured thermal properties; P.M. studied microstructure and texture of alloys; Z.T. and V.Šs. analysed the data; Z.T. and P.L. wrote the paper.

Funding: This study was realized with the support of the Czech Science Foundation under the contract 107-15/11879S. A part of this work was financed by the Ministry of Education, Youth and Sport of the Czech Republic under the research project IRP-IFL-2018.

Conflicts of Interest: The authors declare no conflict of interests.

\section{References}

1. Watanabe, H.; Mukai, T.; Ishikawa, K. Differential speed rolling of an AZ31 magnesium alloy and resulting mechanical properties. J. Mater. Sci. 2004, 36, 1477-1480. [CrossRef]

2. Huang, X.; Suzuki, K.; Saito, N. Textures and stretched formability of Mg-6Al-1Zn magnesium alloy sheets rolled at high temperatures up to 793 K. Scripta Mater. 2009, 60, 651-654. [CrossRef]

3. Chino, Y.; Mabuchi, M.; Kishihara, R.; Hosokawa, H.; Amada, Y.; Wen, C.; Shimojima, K.; Iwasaki, H. Mechanical properties and press formability at room temperature of AZ31 Mg alloy processed by single roller drive rolling. Mater. Trans. 2002, 43, 2554-2560. [CrossRef]

4. Schwarz, F.; Eilers, C.; Krüger, L. Mechanical properties of an AM20 magnesium alloy processed by accumulative roll bonding. Mater. Charact. 2015, 105, 144-153. [CrossRef]

5. Del Valle, J.A.; Pérez-Prado, M.T.; Ruano, O.A. Accumulative roll bonding of a Mg based AZ61 alloy. Mater. Sci. Eng. A 2005, 410-411, 353-357. [CrossRef]

6. Pérez-Prado, M.T.; Del Valle, J.A.; Ruano, O.A. Grain refinement of Mg-Al-Zn alloys via accumulative roll bonding. Scripta Mater. 2004, 51, 1093-1097. [CrossRef]

7. Agnew, S.R. Plastic anisotropy of magnesium alloy AZ31B sheet. In Magnesium Technology; Kaplan, H., Ed.; TMS: Warendale, PA, USA, 2002; pp. 169-174.

8. Bohlen, J.; Chmelík, F.; Dobroň, P.; Letzig, D.; Kaiser, F.; Lukáč, P.; Kainer, K.U. Orientation effects on acoustic emission during tensile deformation of hot rolled magnesium alloy AZ31. J. Alloys Compd. 2004, 378, 207. [CrossRef]

9. Trojanová, Z.; Džugan, J.; Halmešová, K.; Németh, G.; Minárik, P.; Lukáč, P.; Bohlen, J. Influence of accumulative roll bonding on the texture and tensile properties of an AZ31 Magnesium alloy sheets. Materials 2018, 11, 73. [CrossRef] [PubMed]

10. Ying, T.; Zheng, M.Y.; Li, Z.T.; Qiao, X.G. Thermal conductivity of as-cast and as-extruded binary Mg-Al alloys. J. Alloys Compd. 2014, 608, 19-24. [CrossRef]

11. Ying, T.; Zheng, M.Y.; Li, Z.T.; Qiao, X.G.; Xu, S.W. Thermal conductivity of as-cast and as-extruded Binary Mg-Zn alloys. J. Alloys Compd. 2015, 621, 250-255. [CrossRef]

12. Pan, H.; Pan, F.; Peng, J.; Gou, J.; Tang, A.; Wu, L.; Dong, H. High conductivity Binary Mg-Zn sheet processed by cold rolling. J. Alloys Compd. 2013, 578, 493-500. [CrossRef]

13. Zhong, L.; Peng, J.; Sung, Y.; Wang, Y.; Lu, Y.; Pan, F. Microstructure and thermal conductivity of cast and as-extruded Mg-Mn alloys. Mater. Sci. Technol. 2017, 33, 92-97. [CrossRef]

14. Ding, Y.; Zhu, Q.; Le, Q.; Zhang, Z.; Cui, J. Analysis of temperature distribution in the hot plate rolling of Mg alloy by experiment and finite element method. J. Mater. Process. Technol. 2015, 225, 286-294. [CrossRef]

15. Trojanová, Z.; Podrábsky, T.; Lukáč, P.; Armstrong, R.W.; Pesička, J.; Forejt, M. Influence of the strain rate on deformation mechanisms of an AZ31 magnesium alloy. Int. J. Mater. Res. 2013, 104, 762-768. [CrossRef]

16. Ohno, M.; Mirkovic, D.; Schmid-Fetzer, R. Liquidus and solidus temperatures of rich Mg-Al-Zn alloys. Acta Mater. 2006, 54, 3883-3891. [CrossRef]

17. Braszczyńska-Malik, K.N. Discontinuous and continuous precipitation in magnesium-aluminium type alloys. J. Alloys Compd. 2009, 477, 870-876. [CrossRef]

18. Rudajevová, A.; Staněk, M.; Lukáč, P. Determination of thermal diffusivity and thermal conductivity of Mg-Al alloys. Mater. Sci. Eng. A 2003, 341, 152-157. [CrossRef]

19. Su, C.; Li, D.; Ying, T.; Zhou, L.; Li, L.; Zeng, X. Effect of Nd content and heat treatment on the thermal conductivity of Mg-Nd alloys. J. Alloys Compd. 2015, 685, 114-121. [CrossRef]

20. Yamasaki, M.; Kawamura, Y. Thermal diffusivity and thermal conductivity of Mg-Zn-rare earth element alloys with long period stacking ordered phase. Scripta Mater. 2009, 60, 264-267. [CrossRef] 
21. Rudajevová, A.; Lukáč, P. Comparison of the thermal properties of AM20 and AS21 magnesium alloys. Mater. Sci. Eng. A 2005, 397, 16-21. [CrossRef]

22. Lee, S.; Ham, H.J.; Kwon, S.Y.; Kim, S.W.; Suh, C.M. Thermal conductivity of magnesium alloys in the temperature range from $-125^{\circ} \mathrm{C}$ to $400{ }^{\circ} \mathrm{C}$. Int. J. Thermophys. 2013, 34, 2343-2350. [CrossRef]

23. Wang, C.; Cui, Z.; Liu, H.; Chen, Y.; Ding, W.; Xiao, S. Electrical and thermal conductivity in Mg-5Sn alloy at different aging status. Mater. Design 2015, 74, 48-52. [CrossRef]

24. Ying, T.; Chi, H.; Zheng, M.; Li, Z.; Uher, C. Low temperature electrical resistivity and thermal conductivity of Binary magnesium alloys. Acta Mater. 2014, 80, 288-295. [CrossRef]

25. Zhong, L.; Wang, Y.; Gong, M.; Zheng, X.; Peng, J. Effects of precipitates and its interface on thermal conductivity of Mg-12Gd alloy during aging treatment. Mater. Charact. 2018, 138, 284-288. [CrossRef]

26. Zhong, L.; Peng, J.; Sun, S.; Wang, Y.; Lu, Y.; Pan, F. Microstructure and thermal conductivity of as cast and as-solutionized Mg-rare earth binary alloys. J. Mater. Sci. Technol. 2017, 33, 1240-1248. [CrossRef]

27. Zhong, L.; Peng, J.; Li, M.; Wang, Y.; Lu, Y.; Pan, F. Effect of Ce addition on the microstructure, thermal conductivity and mechanical properties of Mg-0.5Mn alloys. J. Alloys Compd. 2016, 661, 402-410. [CrossRef]

28. Li, B.; Hou, L.; Wu, R.; Zhang, J.; Li, X.; Zhang, M. Microstructure and thermal conductivity of Mg-2Zn-Zr alloy. J. Alloys Compd. 2017, 722, 772-777. [CrossRef]

29. Yuan, J.; Zhang, K.; Li, T.; Li, X.; Li, Y.; Ma, M.; Luo, P. Anisotropy of thermal conductivity and mechanical properties in Mg-5Zn-1Mn alloy. Mater. Design 2012, 40, 257-261. [CrossRef]

30. Del Valle, J.A.; Pérez-Prado, M.T.; Ruano, O.A. Texture evolution during large-strain hot rolling of the Mg AZ61 alloy. Mater. Sci. Eng. A 2005, 355, 68-78. [CrossRef]

31. Ion, S.E.; Humphreys, F.J.; White, H.S. Dynamic recrystallization and the development of microstructure during the high temperature deformation of magnesium. Acta Metall. 1982, 30, 1909-1919. [CrossRef]

32. Grimvall, G. Thermophysical Properties of Materials, 1st ed.; Elsevier, North Holland: Amsterdam, The Netherlands, 1999; p. 262. ISBN 9780444827944.

33. Berman, B. Thermal Conduction in Solids; Claredon Press: Oxford, UK, 1976.

34. Uher, C. Thermal conductivity of metals. In Thermal Conductivity: Theory, Properties and Application; Tritt, T.M., Ed.; Kluwer Academic/Plenum Publishers: New York, NY, USA, 2004; ISBN 0-306-48327-0. Available online: ftp:/ / nozdr.ru/biblio/kolxo3/P/PS/PSa/Tritt\%20T.M.\%20(ed.)\% 20Thermal\%20conductivity\%20(Kluwer,\%202004)(ISBN\%200306483270)(O)(306s)_PSa_.pdf (accessed on 11 Apil 2018).

35. Bass, J.; Fisher, K.H. Landolt-Börnstein Database; New Series III/15a; Springer: Berlin/Heidelberg, Germany, 1982. [CrossRef]

(C) 2018 by the authors. Licensee MDPI, Basel, Switzerland. This article is an open access article distributed under the terms and conditions of the Creative Commons Attribution (CC BY) license (http://creativecommons.org/licenses/by/4.0/). 